\title{
Anterior Dental Cutting at Laetolil
}

\author{
MILFORD H. WOLPOFF AND MARY D. RUSSELL \\ Department of Anthropology, University of Michigan, Ann Arbor, Michigan \\ 48109
}

\author{
KEY WORDS $\quad \mathrm{C} / \mathrm{P}_{3}$ complex, Laetolil
}

\begin{abstract}
No evidence supports the interpretation of malocclusion in the LH-14 right $P_{3}$. The pattern of anterior cutting shown in the younger Laetolil specimens has its analogue in the deciduous dentitions of Pongo.
\end{abstract}

In a recent paper White (1981) asserts that the occlusal wear on the right $\mathrm{P}_{3}$ of LH-14 is the result of malocclusion. We find this to be demonstrably incorrect. Although LH-14 is a set of isolated teeth (White, 1977; Wolpoff, 1979), there is evidence indicating that nothing is abnormal about the positioning of this tooth in the tooth row. The mesial interproximal facet is in a normal position, its buccal border is just below the most inferior extension of the mesial ridge, and the facet extends for about 2 $\mathrm{mm}$ lingually. There is a corresponding distal facet on the lower right canine which matches the $\mathrm{P}_{3}$ facet when these teeth are in a normal alveolar position.

There are a number of facets on or adjacent to the distal surface of the right $P_{3}$. Of these, the only one to cover the entire height of the distal face is a concave facet somewhat displaced lingually from the center of the tooth. We believe this is the contact facet for the $\mathrm{P}_{4}$. It is relevant that the most lingual aspect of the distal interproximal facet on the LH-14 $\mathrm{P}_{3}$ is also concave.

Buccal to this LH-14 $\mathrm{P}_{4}$ contact facet are three contiguous, lightly polished facets that extend across most of the remaining distal $P_{3}$ face. These facets, convex on the vertical axis, extend somewhat superiorally onto the occlusal surface, and consequently could not have been formed by interproximal attrition after the tooth had erupted.

We believe that the most lingual (concave) facet represents the mesial buccal contact for a $\mathrm{P}_{4}$ which was rotated clockwise (as seen from above) out of its normal position. In the absence of the actual LH-14 $\mathrm{P}_{4}$ this is impossible to prove, although there is evidence for another occlusal anomaly in this dentition. However, if correct, this rotation would expose the distal buccal face and edge of the $\mathrm{P}_{3}$ to possible occlusal contact with the maxillary teeth, thereby accounting for the two lightly polished, convex facets described above. If the $P_{4}$ were in normal position, the $P_{3}$ would have to be rotated to account for these facets, but the mesial contact with the canine argues against this alternative. The second interpretation is supported by White (1980), who does not recognize the implications of the normally positioned mesial contact facet.

The occlusal condition of the left LH-14 $\mathrm{P}_{3}$ is, as White $(1980,1981)$ noted, at variance with the right tooth. The tooth is generally more worn, a wear plane that is concave on the vertical axis covers most of its distal occlusal face, and there is an unusual wear facet flattening the region surrounding the buccal cusp tip position and extending well onto the buccal face. The differences in the degree of occlusal wear and in its pattern lead us to question whether the left $\mathrm{P}_{3}$ should be attributed to the same specimen as the other isolated teeth comprising LH-14. Morphological differences between the unworn portions of the left and right $\mathrm{P}_{3}$ crowns include a much more pronounced bulge just above the cementoenamel junction on the buccal face on the right tooth, and a greater height of this bulging region above the junction. Thus, we believe that the attribution of these teeth to the same specimen is uncertain.

However, if the association of both $\mathrm{P}_{3}$ 's in the same dentition is accepted, analysis of the contact between the left canine and the left $P_{3}$ shows it is the left premolar that has wear resulting from a malocclusion. The distal interproximal facet on the left canine is much like the one on the right, roughly elliptical in form with the long axis vertical (i.e., parallel with the long axis of the tooth). However, the mesial facet on the left $P_{3}$ differs from its right

Received August 1, 1980; accepted December 11, 1980. 
counterpart. It is slightly concave and has a long axis which is $45^{\circ}$ clockwise from the vertical, as seen from the mesial face. The left canine and $\mathrm{P}_{3}$ facets do not match when both teeth are in normal vertical position relative to each other. However, they match perfectly if the vertical axis of the left $\mathrm{P}_{3}$ is rotated $45^{\circ}$ clockwise, as seen from the distal surface. This rotation would bring the flat occlusal wear facet extending onto the buccal face (described above) fully to the functional occlusal plane, thus accounting for its unusual characteristics.

Such a rotation would also account for an unusual feature of the partially damaged left $P_{4}$. On this tooth, the undamaged lingual portion of the mesial facet is displaced to the buccal corner of the mesial face. Alignment of the adjacent $\mathrm{P}_{3}$ in the rotated position described above would account for an interproximal contact in this position, assuming that the $\mathrm{P}_{4}$ was in a normal occlusal relation in the jaw.

Finally, we have found that both Wolpoff and White were incorrect in their contention that the pattern of wear on the LH-14 right $\mathrm{P}_{3}$ is unknown for any other primate. Discussion of whether or not such a pattern characterizes the younger Australopithecus afarensis specimens from Hadar must await their publication. However, an analogue can be found in the deciduous dentition of Pongo. Young specimens occlude a vertically short maxillary canine against a bicuspid $\mathrm{dm}_{1}$ with a transverse ridge connecting the cusps. In specimens with $M_{1}$ unerupted, there is a distal wear facet on the maxillary dc at a close to $90^{\circ}$ angle to the mesial-distal axis of the tooth. Articulation with the mandibles shows that this facet cannot result from wear across the buccal $\mathrm{dm}^{1}$ face, which in any event is unworn in the specimens in question. Instead, the angle of the canine wear plane exactly corresponds to the wear facet that extends across the mesial face of the $\mathrm{dm}_{1}$, sharpening the transverse ridge. A similar facet extends across the distal $\mathrm{dm}_{1}$ crown face, caused by the mesial portion of the $\mathrm{dm}^{1}$ crown. These occlusal facets parallel those described for the younger Laetolil specimen, except that in the hominid fossils it is a permanent upper canine that demonstrates the transverse distal facet, and a $\mathrm{P}^{3}$ that presumably occludes with the distal $P_{3}$ face. Just as the wear pattern on the $P_{3}$ seems to change with age at Laetolil, the $\mathrm{dm}_{1}$ wear also becomes different in older Pongo individuals. However, in this case the wear shifts to a sharpening action of the maxillary dc against the buccal face of the $\mathrm{dm}_{1}$, analogous to the adult condition in Pongo.

In sum, a very different, and we believe correct, interpretation of the wear on the LH-14 right $P_{3}$ can be contrasted with that suggested by White (1981). We believe there is clear evidence for $\underline{C} / P_{3}$ cutting in this earliest hominid taxon. However, since there is only one tooth involved and because there are positional anomalies on both sides of the LH-14 dentition, the possibility remains that the right $P_{3}$ wear is also anomalous, corresponding to (unknown) problems in the maxillary dentition. Only future discoveries can fully resolve this issue ${ }^{1}$. We have restricted our discussion to the known data. Casts of the specimens in question can be obtained from the National Museums of Kenya at very small cost, and we propose that readers interested in continuing or following up this issue obtain these casts and observe the relevant features for themselves.

\section{ACKNOWLEDGMENTS}

We thank Dr. M. Leakey, discoverer of the Laetolil hominids, for permission to publish observations on the unpublished Laetolil specimens made by M.H. Wolpoff, and D.C. Johanson for permission to observe Pongo specimens at the Cleveland Museum of Natural History.

This research was supported by NSF grant BNS 76-82729.

\section{LITERATURE CITED}

White, TD (1977) New fossil hominids from Laetolil, Tanzania. Am. J. Phys. Anthropol. 46:197-230.

White, TD (1980) Additional fossil hominids from Laetoli, Tanzania: 1976-1979 specimens.Am. J. Phys. Anthropol 53:487-504.

White, TD (1981) On the evidence for "anterior dental cutting" in Laetoli hominids. Am. J. Phys. Anthropol. 54:107-108.

Wolpoff, MH (1979) Anterior dental cutting in the Laetolil hominids and the evolution of the bicuspid $P_{3}$. Am. J. Phys. Anthropol. 51:233-234.

'Publication of the BMNH Laetolil canine (White, 1980) with an obvious honing facet further supports our contention of anterior dental cutting. 